\title{
Regular condom use tends to decrease cervical lesions in resident-commercial sex workers in Sub-Saharan Africa
}

\author{
Efosa Bolaji Odigie* and Peter Uwadiegwu Achukwu**
}

\begin{abstract}
\section{BACKGROUND}

Cervical lesions are abnormalities seen in tissues and cells examined from the uterine cervix. These abnormalities are on the increase and are ignored; thereby constituting major health problems in resident commercial sex workers (CSWs) who temporarily reside in brothels for sex business. Hence, we investigated the associations between behavioural risk factors and cervical lesions in resident commercial sex workers.
\end{abstract}

\section{METHODS}

We conducted a cross-sectional study among 119 resident commercial sex workers using questionnaires as the data gathering tool, liquid-based cytology for cervical lesions screening, and microscopy for examination of slides. Statistical analyses were conducted using Epi- Info ${ }^{\text {TM }}$ version 6.4 and STATISTICA (StatSoft, version 5, 2009 Edition, Atlanta, GA 303294027 USA). Data were analysed using multivariate and simple logistic regression analyses, while the level of significance was set at $\mathrm{p} \leq 0.05$.

\section{RESULTS}

The behavioural risk factors, like smoking and hard drugs, alcohol intake, commercial sex duration, client's daily patronage and sex frequency were not significant apart, but regular condom use tends to decrease the cervical lesions in CSWs $(\mathrm{OR}=0.91 ; 95 \% \mathrm{CI}$ 0.92-1.06), including anal and oral sex $(\mathrm{OR}=0.99$ (95\% CI 0.29-3.60). The patterns of cervical lesions further showed acute and chronic cervicitis with a prevalence of $10.1 \%$, including lowgrade squamous intraepithelial lesion (LSIL) and atypical squamous cells of undetermined significance (ASCUS). We recorded 8/12 (66.7\%) for acute cervicitis, $4 / 12(33.3 \%)$ chronic, and $82.4 \%$ negative.

\section{CONCLUSION}

We suggest that behavioural risk factors are associated with cervical lesions and that regular condom use tends to decrease cervical lesions among resident CSWs.

Keywords: Cervical lesions, behavioural risk factors, resident commercial sex workers, sub-Saharan Africa
*Department of Medical Laboratory Science, School of Basic Medical Sciences, College of Medical Sciences, University of Benin, Benin City, Nigeria **Department of Medical Laboratory Science, Faculty of Health Sciences and Technology, University of Nigeria, Enugu Campus, Enugu, Nigeria

\section{Correspondence:}

Efosa Bolaji Odigie

Histopathology/ Cytopathology Unit Department of Medical Laboratory Science, School of Basic Medical Sciences, College of Medical Sciences, University of Benin, Benin City, Edo State, Nigeria.

Email:bolaji.odigie@uniben.edu Mobile: +2348023345132

Date of first submission, December 18,2017

Date of final revised submission, April 11,2018

Date of acceptance, April 12, 2018

This open access article is distributed under a Creative Commons AttributionNon Commercial-Share Alike 4.0 International License

Cite this article as: Odigie EB, Achukwu PU. Regular condom use tends to decrease the cervical lesions in ResidentCommercial Sex Workers in sub-Saharan Africa. Univ Med 2018;37:39-49. doi: 10.18051/UnivMed.2018.v37.39-49 


\section{INTRODUCTION}

Resident commercial sex workers are females living temporarily in brothels to exchange sex for money from male clients. Their activities may lead to exposure to transmitted sexual infections, which could have uneven impacts on both sexual and reproductive health. ${ }^{(1)}$ This group of women is occupationally exposed to diverse forms of infection making them at increased risk of cervical lesions. In many societies today, due to the variety of social and legal discriminatory issues, sex workers are usually poorly identified and do not have regular Pap smears or have their health status checked in the hospital. ${ }^{(2)}$ In a country like Iran, voluntary counseling and testing (VCT) centers offer services to women at high risk due to their offensive sexual behaviors; yet, a large number of them are unidentified ${ }^{(3)}$ and unscreened. ${ }^{(2)}$ Sex business is rampant in Edo State, Nigeria without adequate government interventions to cater or combat the spread of unforeseen diseases, ${ }^{(1)}$ which may be recycled between the female sex workers and their male clients. There exist different methods for cervical lesions screening and the most successful in the reduction of the incidence and mortality in commercial sex workers is the screening by Papanicolaou smear. ${ }^{(4,5)}$

Early detection of cervical lesions has excellent prognosis ${ }^{(4)}$ and is one of the most efficient ways of diagnosing the disease at an early pre-cancerous stage. ${ }^{(5)}$ Cervical lesions in some region revealed a prevalence of $16.5 \%$ in resident commercial sex workers in Iran, ${ }^{(2)}$ $12.46 \%$ in Hong Kong $^{(3)}$ and $21 \%$ in another survey reported in Shenyang, China. ${ }^{(4)}$ Various studies reported the behavioral risk factors as age at having first sexual intercourse, oral sex, anal intercourse, smoking, hard drugs and substance abuse ${ }^{(1)}$, alcoholism, ${ }^{(2)}$ multiple sex partners, and present and previous history of sexually transmitted diseases or infections. ${ }^{(3,4)}$ However, they were not associated with cervical lesions in the general sex worker's population as reported in another literature. ${ }^{(6)}$
Although a dearth of studies examining behavioral risk factors for cervical lesions among sex workers remains, data are available on patterns of cervical lesions in the women's population ${ }^{(2,4)}$ but not in resident sex workers. Among sex workers in Hong Kong; ${ }^{(3)}$ difficulty in accessing resident sex workers, failure to keep up with appointments, withdrawal from screening, and the fear of the screening procedure has been reported. An observational study in Shenyang, China ${ }^{(4)}$ reported on a range of behavioral factors to cervical lesions among female sex workers. It includes contraception method, failure to attend regular Pap tests screening, bleeding after coitus, a lack of education surrounding cervical lesions, educational status of sex workers and numerous partners. Other factors like the avoidance of health care due to fear of stigmatisation (1) and policing due to the fear of arrest ${ }^{(6)}$ have also been identified as barriers to screening exercise by resident CSWs; in addition to the fact that they deprive themselves of the routine health care access for fear of identity exposures. These events necessitated the need to explore further the association between behavioral risk factors and cervical lesions in sex workers. There is, therefore, a need for full-scale behavioral and disease pattern studies on these occupationally exposed women, to understand the best preventive and or treatment plans available to the clinicians. Against this backdrop, we investigated the behavioral risk factors associated with cervical lesions in resident CSW

\section{METHODS}

\section{Research Design}

We conducted a cross-sectional study using questionnaires as the data gathering tool, liquidbased cytology for cervical lesion screening, and microscopy ${ }^{(7)}$ for examination of slides. The study lasted from January 2016 to September 2017.

\section{Study Area}

This study was conducted among commercial sex workers plying their trade within 
the four local government areas (LGAs) that make up Benin City in Edo State, Nigeria [Figure 1]. Benin City is the most extensive urban center and state capital, while Nigeria is the most extensive country in sub-Saharan Africa. ${ }^{(8)}$

\section{Research subjects}

The subjects were females (aged 13-42), who took commercial sex as occupation and were resident in brothels strictly for sex business. The resident CSWs were adequately briefed on the conduct and protocol of the research. Informed consent before sample collection was obtained after the research had been explicitly explained to the participants in English, vernacular (Pidgin English), and local dialects (where possible). Participation was voluntary without any form of inducement or coercion. Female CSWs with healthy or unhealthy cervix and those with a suspected malignancy, which may be a visible growth with an irregular surface, were included in this study. Meanwhile, pregnant CSWs and those who had undergone hysterectomy, including those who received any prior treatment relating to cervical neoplasia, were excluded.

\section{Sample size determination}

The sample size was determined using the formula $\mathrm{n}=\frac{4 \mathrm{PQ}}{\mathrm{L}^{2}}$

where $\mathrm{n}=$ sample size, $\mathrm{P}=$ prevalence of cervical lesions in resident $\mathrm{CSW}$ s from a previous study and $\mathrm{Q}=1-\mathrm{P}$, while $\mathrm{L}$ is $5 \%$ level of precision adopted from Odigie et al. ${ }^{(8)}$ Initially, 178 subjects were recruited for the study. However, 59 subjects were unable to continue due to a clash of interest (clashes between sampling time and day, and sex business, which subjects were unable to forego). Some could not abide by rules governing cervical screening, i.e. avoidance of vaginal intercourse, all forms of douching (use of tampons, medicinal vaginal cream or contraceptive cream) for the duration of 24-48hrs before Pap smear uptake.

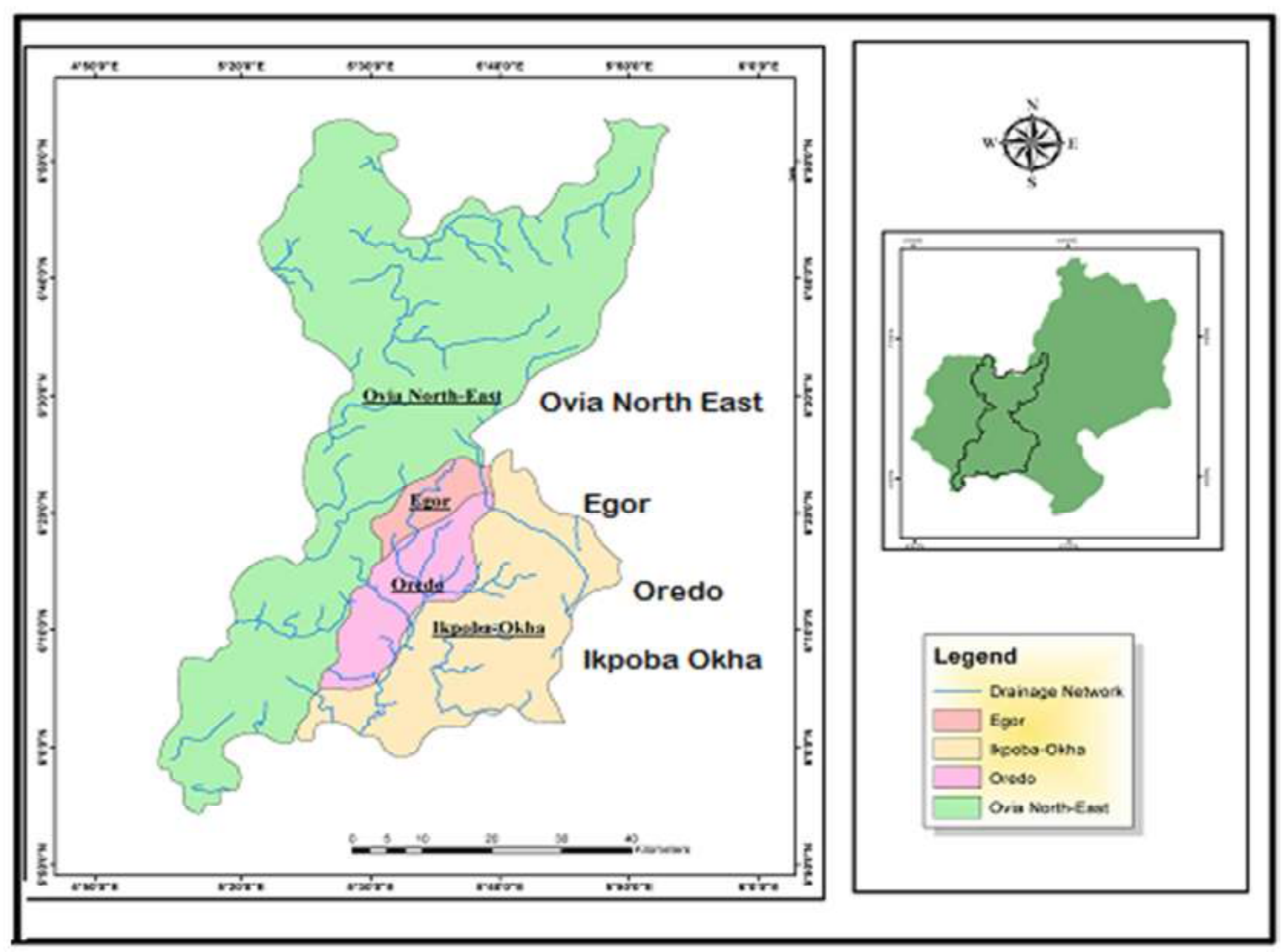

Figure 1. Showing Geographical Location of the four LGAs in Benin City, Nigeria 


\section{Data collection}

A probabilistic simple random sampling method was undertaken in Benin metropolis, Nigeria, in which a cross-sectional approach was used. A structured paper questionnaire was privately administered for data gathering by trained interviewers, covering sociodemographic characteristics and sexual behavior of the subjects. The research questions were predominantly in a multiple-choice format and open-ended in some aspects. The study questions also include the health-care-seeking activities and sexual performances, together with the number of sexual contacts and history of current and former symptoms. Questionnaires were completed voluntarily and conducted in the vernacular (Pidgin English) where necessary.

\section{Sample collection}

We collected samples using the liquidbased cytology (LBC) method (SurePath ${ }^{\mathrm{TM}}$; BD TriPath, Burlington, NC, USA) involving the speculum for inspection of the cervix for lesions or inflammation in the sampled areas. ${ }^{(5,8)} \mathrm{A}$ consultant gynecologist examined the cervix for lesions or inflammation and was assisted by a trained gynecological nurse for the collection of the LBC smears. Clinical signs potentially indicating cervical lesions, e.g., cervical discharge, pus on the cervical swab, bleeding after sampling, and inflammatory cervix were noted. Details of the data and sample collection, smear preparation [using the Cytospin (IEC 61010 Thermo Scientific Cytospin 4, GMI, Inc. USA)], sample processing and staining methods in the present study have been documented. ${ }^{(5,9)}$ Examination of slides were conducted blindly according to Nayar and Wilbur, ${ }^{(7)}$ by more than two consultant pathologists during routine slides reading.

\section{Data analysis}

A descriptive statistical method was used in analysing the results, which were represented as whole numbers and percentages in tabular form. All statistical analyses were conducted using Epi-InfoTM version 6.4 and STATISTICA (StatSoft, version 5, 2009 Edition, Atlanta, GA 30329-4027 USA). Data were analysed using multivariate and simple logistic regression analyses, and the differences were considered significant at $\mathrm{p}<0.05$.

\section{Ethical clearance}

We obtained ethics permit from the Edo State Ministry of Health (Protocol number: HA. 577/Vol.11.165). We also obtained written informed consent from the subjects before data and sample collections. The brothel managers gave the consent on behalf of teenage sex workers as they are below the age of consent. Teenagers in this study fell within the age range of 13-19 years, which was adopted from Odigie et al. ${ }^{(8)}$ Our study was conducted in compliance with the ethical principles for medical research involving human subjects stated in the Helsinki's Declaration of World Medical Association.

\section{RESULTS}

One hundred and nineteen (119) resident commercial sex workers (CSWs) were sampled and screened in the present study. Sixteen sex workers from one hundred and nineteen subjects $(16 / 119)$ were cervical lesion-positive, representing $13.4 \%$ of the study population suffering from cervical lesions in Benin City alone. The patterns of cervical lesions showed that cervicitis $(12 / 119$ or $10.1 \%)$ is common among resident CSWs in this part of the subSaharan Africa. Our findings further revealed that acute cervicitis $(8 / 119$ or $6.7 \%)$ is the leading type of cervical lesion affecting sex workers and is closely followed by chronic cervicitis (4/12 or 33.3\%). Cytology profiles of sex workers revealed that 98/119 (82.4\%) of the resident CSWs are negative for cervical lesion; 04/119 (3.4\%) are abnormal having 2 cases of a low-grade squamous intraepithelial lesion (LSIL) and atypical squamous cells of undetermined significance (ASCUS) each. Inflammatory smears $(12 / 119$ or $10.1 \%)$, and 
unsatisfactory smears $(5 / 119$ or $4.1 \%)$ are observed within the confines of 37 brothels across the 4 LGAs in Benin City (Table 1, Figure 2). Multivariate and simple logistic regression was conducted to understand the effect of age, customer daily patronage, sex duration, condom usage, consumption of alcohol, hard drugs, anal intercourse, oral sex practices and age at first exposure as the likelihood that resident CSWs in Benin City may be exposed to cervical lesions. Age range 13-19 years was selected as baseline comparison as a dummy variable. Commercials sex workers within the age category of 20-39 years have odds of developing cervical lesions that was 1.254 (95\% CI $0.452-2.684)$ of the odds of someone who is within the age range of 13-19

Table 1. Distribution of Participants' Characteristics ( $\mathrm{n}=119)$

\begin{tabular}{|c|c|}
\hline Variable & Number (\%) \\
\hline \multicolumn{2}{|l|}{ Age (years) } \\
\hline $13-19$ & $34(28.57)$ \\
\hline $20-39$ & $63(52.94)$ \\
\hline $40-59$ & $17(14.29)$ \\
\hline 60 and above & $5(4.2)$ \\
\hline \multicolumn{2}{|l|}{ Levels of Education } \\
\hline Primary School drop out & $27(22.69)$ \\
\hline Primary education & $56(47.06)$ \\
\hline Secondary school drop out & $30(25.21)$ \\
\hline Secondary education and more & $6(5.04)$ \\
\hline \multicolumn{2}{|l|}{ Brothels Visited Per LGA $(n=37)$} \\
\hline Egor & $11(29.73)$ \\
\hline Ikpoba-Okha & $7(18.92)$ \\
\hline Oredo & $14(37.84)$ \\
\hline Ovia North-East & $5(13.51)$ \\
\hline \multicolumn{2}{|l|}{ Type of sex workers } \\
\hline Resident & $119(100)$ \\
\hline Teenage & $34(28.57)$ \\
\hline Migrant & $89(74.79)$ \\
\hline \multicolumn{2}{|l|}{ Cervical Lesions } \\
\hline Cervicitis & $12(10.1)$ \\
\hline Acute cervicitis & $8(6.7)$ \\
\hline Chronic cervicitis & $4(3.4)$ \\
\hline ASCUS & $2(1.7)$ \\
\hline LSIL & $2(1.7)$ \\
\hline \multicolumn{2}{|l|}{ Classification of Smears } \\
\hline Normal & $98(82.4)$ \\
\hline Abnormal & $4(3.4)$ \\
\hline Inflammatory & $12(10.1)$ \\
\hline Unsatisfactory & $5(4.1)$ \\
\hline \multicolumn{2}{|l|}{ Behavioural Factors } \\
\hline Condom Usage & $93(78.2)$ \\
\hline Smoking cigarette \& hard drugs Usage & $79(66.4)$ \\
\hline Cigarette alone & $37(31.1)$ \\
\hline Hard drugs alone & $3(2.5)$ \\
\hline Drinking habit (alcohol intake) & $107(89.9)$ \\
\hline Anal and Oral Sex Practices & $87(73.11)$ \\
\hline Anal intercourse only & $19(15.97)$ \\
\hline Oral sex only & $13(10.92)$ \\
\hline Mean Commercial Sex Duration & 52.64 months \\
\hline Mean Client's Daily Patronage & 11.26 clients per day \\
\hline Mean Sex Frequency & 17.12 rounds of sex per day \\
\hline
\end{tabular}

Note: Resident CSWs: commercial sex workers who are mainly resident in brothels. Teenage CSWs: commercial sex workers who are teenagers and as such, they are below the age of consent and are resident in brothels for sex business. Migrant CSWs: commercial sex workers who are from other countries but are resident in brothels as sex workers. ASCUS: Atypical Squamous Cells Of Undetermined Significance. LSIL: Low-grade squamous intraepithelial lesion 


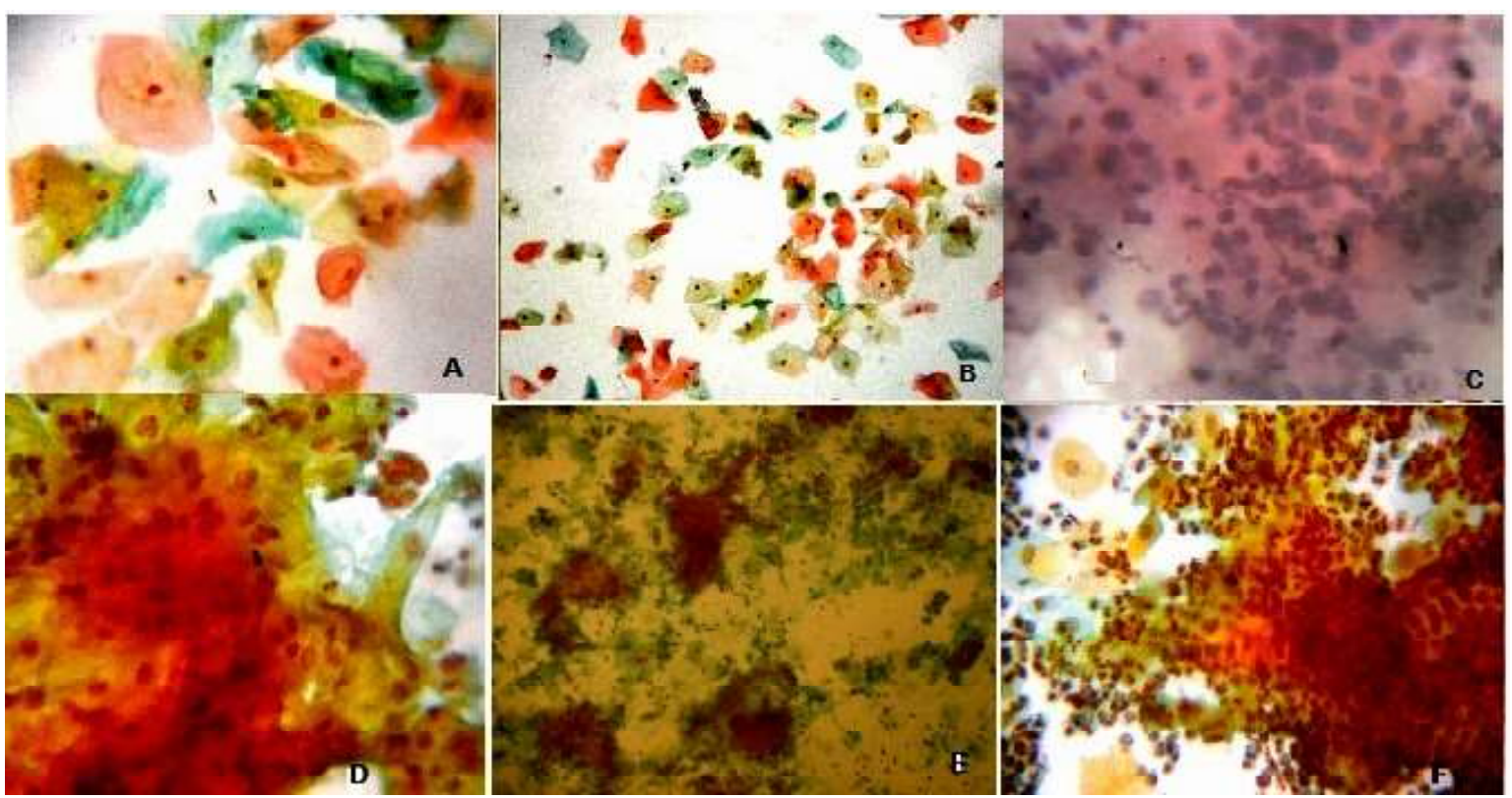

Figure 2. Patterns of cervical lesion in resident CSWs in 4 LGAs in Benin City, Edo State, Nigeria (A= Negative for cervical lesion, stained with the modified Pap staining method at X40 magnification, $B=$ Negative LBC slide at X10 magnification, $\mathrm{C}=$ chronic cervicitis, $\mathrm{D}=$ low grade squamous intraepithelial lesions, $\mathrm{E}=$ atypical squamous cells of undetermined significance and $\mathrm{F}=$ acute cervicitis

years, but statistically not significant. Consequently, the respondents within the age range of 40-59 years $(\mathrm{OR}=1.254 ; 95 \%$ CI $0.452-2.689)]$ were more likely to develop cervical lesion than the ones within the reference age, but statistically not significant. CSWs with a primary school degree have odds of

Table 2. Simple Logistic Regression Analysis of Risk Factors for Cervical Lesions in CSWs ( $\mathrm{n}=119)$

\begin{tabular}{|c|c|c|c|}
\hline \multirow{2}{*}{ Variables } & \multicolumn{2}{|c|}{ Cervical Lesions } & \multirow{2}{*}{ OR $(95 \% \mathrm{CI})$} \\
\hline & Yes $(n=16)$ & No $(n=103)$ & \\
\hline \multicolumn{4}{|l|}{ Age (Years) } \\
\hline $13-19 *$ & 05 & 27 & 1.000 \\
\hline $20-39$ & 08 & 52 & $0.208(0.242-1.467)$ \\
\hline $40-59$ & 02 & 18 & $1.254(0.452-2.684)$ \\
\hline 60 and above & 01 & 06 & $0.104(0.646-2.339)$ \\
\hline \multicolumn{4}{|l|}{ Levels of Education } \\
\hline Primary school dropout* & 04 & 16 & 1.000 \\
\hline Primary Education & 07 & 39 & $0.330(0.567-2.527)$ \\
\hline Secondary school dropout & 03 & 31 & $0.871(0.231-2.668)$ \\
\hline Secondary education and more & 02 & 17 & $1.140(0.428-2.251)$ \\
\hline \multicolumn{4}{|l|}{ Commercial Sex Duration } \\
\hline 0-24 months* & 06 & 46 & 1.000 \\
\hline 25-84 months & 07 & 33 & $0.961(0.411-1.764)$ \\
\hline 85 months and above & 03 & 24 & $0.932(0.232-1.624)$ \\
\hline \multicolumn{4}{|l|}{ Client's Daily Patronage } \\
\hline $0-10^{*}$ & 07 & 68 & 1.000 \\
\hline $11-20$ & 06 & 19 & $0.238(0.232-1.212)$ \\
\hline 21 and above & 03 & 16 & $1.200(0.425-1.463)$ \\
\hline \multicolumn{4}{|l|}{ Sex Frequency } \\
\hline $0-12 *$ & 08 & 57 & 1.000 \\
\hline $13-25$ & 05 & 31 & $0.283(0.561-2.687)$ \\
\hline 26 and above & 03 & 15 & $2.024(0.463-2.682)$ \\
\hline \multicolumn{4}{|l|}{ Age at first Exposure } \\
\hline $0-10$ & 05 & 06 & 1.000 \\
\hline $11-15$ & 09 & 93 & $0.063(0.291-2.164)$ \\
\hline 16 and above & 02 & 04 & $1.379(0.532-1.763)$ \\
\hline
\end{tabular}


Table 3. Multivariate logistic regression analysis of behavioral risk factors for cervical lesions in Resident CSWs ( $\mathrm{n}=119)$

\begin{tabular}{|c|c|c|c|}
\hline \multirow{2}{*}{ Behavioral Risk Factors } & \multicolumn{2}{|c|}{ Cervical Lesions } & \multirow{2}{*}{$\begin{array}{c}\text { COR } \\
(95 \% \text { C.I })\end{array}$} \\
\hline & Yes $(n=16)$ & No $(n=103)$ & \\
\hline \multicolumn{4}{|l|}{ Regular condom use } \\
\hline Yes & 9 & 83 & $0.91(0.09-1.06)$ \\
\hline No & 7 & 20 & \\
\hline \multicolumn{4}{|l|}{ Smoking and use of hard drugs } \\
\hline Yes & 11 & 71 & 0.99 \\
\hline No & 5 & 32 & $(0.29-.4 .60)$ \\
\hline \multicolumn{4}{|l|}{ Drinking habit (alcohol intake) } \\
\hline Yes & 16 & 101 & 1.02 \\
\hline No & 0 & 2 & $(0.99-1.05)$ \\
\hline \multicolumn{4}{|l|}{ Anal and oral Sex Practices } \\
\hline Yes & 13 & 79 & 1.32 \\
\hline No & 3 & 24 & $(0.31-6.32)$ \\
\hline
\end{tabular}

Note : All the behavioral risks factors are dichotomous variables coded as yes and no. Condom usage assumes two levels, i.e. "regular condom usage" [Yes or 1] and "occasional condom usage" [No or 2]. The default value, (i.e. yes) was used as the reference category. Since the p-value for regular condom usage was not significant, it could be suggested that the sex workers who use condoms occasionally are more likely to develop cervical lesions compared with those that do not. It further implies that regular condom users are 0.91 less likely to develop cervical lesions compared to those using condoms occasionally

decreased cervical lesions that was $(\mathrm{OR}=0.3095 \%$ CI 0.563-2.527) of the odds of a primary school dropout sex worker. For example, sex workers with secondary school dropouts tend to decrease cervical lesion compared to primary school drop out.but statistically not significant $(\mathrm{OR}=0.871 ; 95 \%$ CI 0.231-2.682) (Table 2).

The demographics (age and education) and some risk factors (customer daily patronage, sex duration, consumption of alcohol, hard drugs, and age at first exposure) were not significant ( $>0.005$ ) (Table 2), except that regular condom use tended to decrease the risk of cervical lesions $(\mathrm{OR}=0.91 ; 95 \%$ CI $0.09-1.06)$, but was statistically not significant in the exposure of resident CSWs to cervical lesions (Table 3).

\section{DISCUSSION}

The prevalence of cervical lesion has been reported to be increasing in females or transactional sex workers, ${ }^{(10)}$ which indeed calls for concerns. Our study showed that cervicitis $(12 / 119$ or $10.1 \%)$ is on the rise amongst the resident CSWs. It, however, supersedes the lowgrade squamous intraepithelial lesions and the atypical squamous cells of undetermined significance both having 4/119 (3.4\%); which aligns with the report by Vorsters et al. ${ }^{(9)}$ that cervical cancer is commoner among women who have been in transactional sex work for a long time and women who have multiple sex partners. ${ }^{(11)}$ In buttress, we found that the majority of the affected women have been engaged in sex work for a longer duration than their counterparts who are not affected (Table 1). However, our finding is not consistent with the report in Enugu State, Nigeria, ${ }^{(1)}$ with cervicitis among commercial sex workers amounting to $7.6 \%$. The disparity may be due to an uncommon screening of cervical lesions in resident commercial sex workers in Edo state, compared to Enugu, ${ }^{(1)}$ Nigeria and other areas in sub-Saharan Africa ${ }^{(9,12)}$ that already have cervical lesion or Pap smear screening programmes for sex workers. ${ }^{(13)}$ Bhar et al. ${ }^{(13)}$ reported that Pap screening with HPV testing is one of the sure ways of detecting cervical cancer. Blood or smear HPV testing (serology) and molecular methods are commonly used methods in this era, which complements the result from Pap smears. According to Singh et al., ${ }^{(14)}$ examination by LBC technique remains the standard gold method for cancer screening worldwide.

We also observed a case of a low-grade squamous intraepithelial lesion (LSIL) and atypical 
squamous cells of undetermined significance (ASCUS) representing 04/119 (3.4\%), which did not corroborate with the prevalence that was reported in India. ${ }^{(14)}$ Singh et al. ${ }^{(14)}$ found abnormalities in the form of HSIL and ASCUS relating to $2(1.6 \%)$ in female sex workers, as subsequently confirmed by biopsy. One each was reported in two females, and both of them were positive for HPV 16. This procedure may explain the slight variation in our study compared to Singh et al. ${ }^{(14)}$ in that we did not examine by biopsy and HPV testing, thus confirming the need for periodic screening among sex workers to identify early cervical abnormalities. Conversely, the abnormalities observed in the present study have been reported by Vafaei et al. ${ }^{(2)}$ where they detected the emergence of LSIL, HSIL and ASCUS amongst female sex workers in Iran, which is comparable with our study in Benin City, Nigeria (Table 1, Figure 2).

Other results showed that $84.2 \%$ of our study population was negative for cervical lesion. This information partially agrees with the rate observed in another study among Hungarian female sex workers, ${ }^{(15)}$ where $82.4 \%$ are negative for cervical lesion but dissimilar to the $88 \%$ reported in obstetrics and gynaecology clinics in Nnewi, Nigeria. ${ }^{(16)}$ We also disagree with the study conducted among women with unhealthy cervix in a rural population of a developing country ${ }^{(17)}$ in which normal smear showed (58\%) from the entire participants screened. The disparity may be due in part to sample size and study population, and have been reported. ${ }^{\left({ }^{8}\right)}$ Odigie et al ${ }^{(8)}$ argued on sample and population sizes that these factors play a vital role in research involving sex workers in that the subjects believe their identity may not be adequately protected and as such indirectly affects the study output. Also, pathologists' bias as to what quantity/extent of the presence of inflammatory cells in a cervical smear constitutes an infection seems not to be in favour of this study. Susceptibilities to bias from misclassification of the results by the pathologists in massive screening exercises have been reported. ${ }^{(17)}$ According to Moriarty et al. ${ }^{(18)}$ about the Tahoe study, when cytologists review a Pap test result with the knowledge of positive HPV status, epithelial cell abnormality is more likely to be identified than without knowledge of the HPV status; this is another type of reportage bias.

To ensure accuracy and conformity to standard research roles and procedures, we repeated the examination of subjects with unsatisfactory smears after 3 months, and we found all to be negative for cervical lesion. Although, some subjects were sited at entirely different locations other than the scene at first contact/screening; in addition to an observation that the younger a commercial sex worker is, the more patronage in the sales of sex that she gets, which translates to increase chances of acquiring sexually transmitted diseases. ${ }^{(19)}$ Again, the larger the family size of residentCSWs, the more tendency to having different social characters in the family. Our study, however, is in agreement with Gaya et al. ${ }^{(20)}$ where poverty as a result of large family sizes has been linked to prostitution and could serve as reservoirs for diseases that may lead to cervical lesion. We also observed that the Oredo LGA in Benin City, Nigeria had the highest influx of both migrant $27 / 89(30.3 \%)$ and teenage 13/ $34(38.2 \%)$ resident CSWs (Table 1). This information slightly disagrees with Odigie and Achukwu, ${ }^{(1)}$ who screened CSWs for cervicitis and came up with the report that $47.4 \%$ were teenagers and were resident in brothels. However, this is near consonance with the $40.8 \%$ of the teenage resident CSWs being migrants from other states of the country. Sample size and floating of the resident CSWs have been reported to be responsible for the variations in the reports of different kinds of literature. ${ }^{(21)} \mathrm{In}$ the present analysis sample size may not play a role in determining the accuracy of our report, but this could be attributed to the meandering way in which sex workers operate in order to protect their identity. Recall that the former ${ }^{(1)}$ screened 118 sex workers, while the present study investigated 119 subjects both from the resident commercial sex workers' ring. 
Additionally, more of the subjects are barely educated with basic education, and from an impoverished background (Table 1). Our study, thus, substantiates the finding in Kano, ${ }^{(19)}$ Nigeria where a significant part of the people screened for cervical cancer have low literacy level, and some have an existing socio-cultural practice of polygamy, which predisposes to multiple sexual partners, with the women tending to have a large number of children. In support of this, Hazra et al. ${ }^{(15)}$ reported that carcinomas of the cervix have not only a biomedical spectrum but also have an extensive cultural and socio economic background associated with poverty.

The main focus of this study is dissimilar to the report by Vafaeiet al. ${ }^{(2)}$ whose finding showed a non-significant association between cervical infection and age at first intercourse, contraception method, bleeding after coitus, number of partners, educational status, or drug abuse, and are found to have no correlation with cervical abnormalities. ${ }^{(2)}$ Our result demonstrated a different trend in the demographics and behavioural risk factors where age, education, daily customer patronage, sex period, consumption of alcohol, hard drugs, and age at first exposure have an insignificant association, except that regular condom use tends to decrease cervical lesions and thus conforms with the findings by Vafaei et al. ${ }^{(2)}$ To corroborate our result, Jia et al. ${ }^{(4)}$ revealed in their study a significant association for age of first sexual intercourse and a host of other variables that are not similar to the present result. Several kinds of literature have reported on the key behavioural risk variables, which are in association with cervical lesion. ${ }^{(10,14,17)}$

For clarity, we refer to age at first exposure to sexual intercourse as the age at which the subjects started to have sex either willfully, forcefully or otherwise. Commercial sex duration relates to the entire months or years in which subjects have spent in the commercial sex business. ${ }^{(19)}$ Client's daily patronage is the average number of customers patronising the subjects in a single day. ${ }^{(21)}$ Sex frequency is the average number of performances by male clients that sex workers can accommodate in one day. ${ }^{(22)}$ Condom usage is the total number and percentages of safe sex by sex workers involving commercial sex and regular sex with partners. ${ }^{(19)}$ The use of hard drugs amounts to the act of taking banned substances like marijuana ${ }^{(23,24)}$ and heroin ${ }^{(24,25)}$. Drinking and smoking in this study were also defined as oral consumption of alcohol either socially, indiscriminately or regularly ${ }^{(26)}$ and the habit of smoking cigarettes in like manner ${ }^{(23)}$ to either ease tension or surpass depression. ${ }^{(27)}$ Anal sex practices in our context are the use of the anus for sexual activities $^{(25)}$ and are used on demand by clients or as an alternative to vaginal sex whenever the subject is in her menstrual flow. ${ }^{(21,25)}$

Laslett et al. ${ }^{(22)}$ suggest that drug users may engage in sex work as a way to either purchase drugs or exchange services for drugs, while some sex workers may come to use hard drugs as means to cope with social problems. The study results of Coleman-Cowger et al. (23) conform to our study (Table 2), where resident CSWs are seen buying and selling hard drugs and making indiscriminate use of it. The floating and relocation pattern exhibited by resident sex workers is thought to be restricted to the street sex workers ${ }^{(25)}$ alone due to the nature of their business (moving from one part of the city to another searching for male clients). However, floating and relocation have continually been the tactics that are commoner among sex workers. It is, therefore, necessary to note this attribute associated with female sex workers, ${ }^{(17)}$ transactional, ${ }^{(43)}$ commercial, ${ }^{(19)}$ street ${ }^{(21,25)}$ and resident commercial sex workers ${ }^{(8)}$ as it poses the most significant challenge faced by researchers.

Financial constraints limited our study to cytopathology assessment of cervicitis and cervical cytology using the LBC method only. However, a more comprehensive range of tests would have to be done, including HIV, syphilis, herpes, chlamydia, gonorrhoea and trichomonas testing to complement the present findings. 
Secondly, this study dealt solely with resident commercial sex workers; we had difficulties in assessing the street sex workers, which is also due to the roaming nature of this particular group of sex workers.

Our study was approached in the context of a rights-based reproductive health intervention for the resident commercial sex workers, which also covers aspects like contraception (condom usages).

In the future, researchers are encouraged to include a wide range of tests with the use of molecular pathology and immunohistochemistry for the assessment of cervical lesion in the general population of sex workers.

\section{CONCLUSIONS}

We conclude that the behavioral risk factors like regular condom users tending to decrease cervical lesion among resident CSWs, especially cervicitis. However, early detection of LSIL and ASCUS in our study may help reduce mortality among sex workers.

\section{FINANCIAL SUPPORT AND SPONSORSHIP}

This survey is self-sponsored.

\section{CONFLICTS OF INTEREST}

No conflicts declared.

\section{ACKNOWLEDGEMENTS}

The authors appreciate the members of Sexual Health Concerns for Commercial Sex Workers (SHCCSW) Research Group, University of Benin for providing a workforce for the administration of questionnaires.

\section{CONTRIBUTORS}

All authors contributed to the conception and design of the study, field exercise, acquisition of samples and data, laboratory and data analysis, and interpretation. All authors critically revised the manuscript for valuable intellectual content. BEO contributed to the drafting of the manuscript. PUA read and approved the final draft. All authors made significant contributions that warrant authorship. BEO acted as the corresponding author on behalf of others. All authors have read and approved the final manuscript

\section{FUNDING}

Tertiary Education Trust Funds (TETFUND), University of Benin Research and Publication Committee (URPC), Sexual Health Concerns for Commercial Sex Workers (SHCCSW) Research Group, UNIBEN, Edo State Ministry of Health, Dr P.U. Achukwu and Mr B.E. Odigie respectively.

\section{REFERENCES}

1. Odigie BE, Achukwu PU. Cytopathological examination and epidemiological study of cervicitis in commercial sex workers (CSWs) in Coal City (Enugu), Nigeria. Ethiopian J Health Sci 2015;25:227-32. DOI: http://dx.doi.org/10.4314/ ejhs.v25i3.5.

2. Vafaei H, Asadi N, Foroughinia L, et al. Comparison of abnormal cervical cytology from HIV positive women, female sex workers and general population. Intl J Community Based Nurs Midwifery 2015;3:76-83.

3. Leung KM, Yeoh GP, Cheung HN, et al. Prevalence of abnormal Papanicolaou smears in female sex workers in Hong Kong. Hong Kong Med J 2013;19:203-6. doi: 10.12809/hkmj133917.

4. Jia $H$, Wang $X$, Long $Z$ et al. Human papillomavirus infection and cervical dysplasia in female sex workers in Northeast China: an observational study. BMC Public Health 2015; 15 : 695. doi: 10.1186/s12889-015-2066-X.

5. Sreedevi MT, Usha BS, Sandhya S. Pap smear image-based detection of cervical cancer. Intl J Comp Appl 2012;45:35-2.

6. Duff P, Ogilvie G, Shoveller J, et al. Barriers to cervical screening among sex workers in Vancouver. Am J Public Health 2016;106:366-373. doi: 10.2105/AJPH.2015.302863 
7. Nayar R, Wilbur DC. The pap test and Bethesda 2014. Cancer Cytopathol 2015;123:1-11. doi: 10.1159/000381842.

8. Odigie BE, Achukwu PU, Bello ME. Neuro-fuzzy implementation for cervical lesions screening in commercial sex workers. Intl J Med Eng Inform 2018;10:1-18.

9. Menon S, Broeck D, Rodolfo R, et al. Multiple HPV infections in female sex workers in Western Kenya: implications for prophylactic vaccines within this sub-population. Infect Agents Cancer 2017;12:2. doi: 10.1186/s13027-016-0114-5.

10. Vorsters A, Tine C, Elke L, et al. Prevalence of high-risk human papillomavirus and abnormal pap smears in female sex workers compared to the general population in Antwerp, Belgium. BMC Public Health 2016;16:477. doi: 10.1186/s12889016-3099-5.

11. Soohoo M, Blas M, Byraiah G, et al. Cervical HPV infection in female sex workers: a global perspective. Open AIDS J 2013;7:58-66.

12. Ting J, Mugo N, Kwatampora J, et al. High-risk human papillomavirus messenger RNA testing in physician- and self-collected specimens for cervical lesion detection in high-risk women, Kenya. Sex Transm Dis 2013;40:584-9. doi: 10.1097/ OLQ.0b013e31828e5a91.

13. Bhar VS, Gupta N, Singh MP, et al. Human papillomavirus (HPV) types 16 and 18 in liquidbased cervical cytology samples. Virchows Arch 2015;466:711-5. doi: 10.1007/s00428-015-1750-7.

14. Singh MP, Kaur M, Gupta N, et al. Prevalence of high-risk human papillomavirus types and cervical smear abnormalities in female sex workers in Chandigarh, India. Ind J Med Microbiol 2016;34: 328-34. doi: 10.4103/0255-0857.188325.

15. Hazra SK, Maiti S, Chaudhuri A, et al. Cervical cancer in women with unhealthy cervix in a rural population of a developing country. J Basic Clin Reprod Sci 2013;2:97-100. doi: 10.4103/2278960X.118648.

16. Nwosu OB, Okafor CI, Obiechine NJ, et al. The pattern of cervical cytology in obstetrics and gynaecology clinics in Nnewi, South-Eastern Nigeria. Orient J Med 2010;22:25-8. DOI: http:// dx.doi.org/10.4314/ojm.v22i1-4.63578.

17. Marek E, Dergez T, D2 cruz G, et al. Human papillomavirus infections among Hungarian female sex workers. Eur J Cancer Care 2014;23:6575. doi: $10.1111 /$ ecc. 12110
18. Moriarty AT, Nayar R, Arnold T, et al. The Tahoe Study: bias in the interpretation of Papanicolaou test results when human papillomavirus status is known. Arch Path Lab Med 2014;138:1182-85. doi: 10.5858/arpa.2012-0115-CP.

19. Moeen UD, Irum S, Umaira Z. Knowledge, attitude and practices of female sex workers about HIV/ AIDS prevention in Lahore, Pakistan. Intl J Perceptions Public Health 2017;1:148-156.

20. Gaya SA, Yakasai IA, Muhammad AZ, et al. Cancer of the cervix in unscreened West African women. J Basic Clin Reprod Sci 2012;1:44 8. doi: 10.4103/2278-960X.104296.

21. Odigie BE, Achukwu PU. Street sex occupational exposure to viral infections in Benin City, Nigeria: a call for global awareness. J Appl Sci Res 2017;13: $1-10$.

22. Laslett AM, Jiang H, Room R. Alcohol's involvement in an array of harms to intimate partners. Drug Alcohol Rev 2017;36:72-79. doi: 10.1111/dar.12435.

23. Coleman-Cowger VH, Schauer GL Peters EN. Marijuana and tobacco co-use among a nationally representative sample of US pregnant and nonpregnant women: 2005-2014 National Survey on Drug Use and Health findings. Drug Alcohol Dependence 2017;177:130-135. doi: 10.1016/j.drugalcdep.2017.03.025.

24. Oguntayo AO, Zayyan M, Kolawole AO, et al. Cancer of the cervix in Zaria, Northern Nigeria. Ecancer Med Scie 2011;5:219-25. doi: 10.3332/ ecancer.2011.219.

25. Neal N, Schrader T, Hyndman J, et al. Street-based sex workers need assessment for Toronto, Barrie and Oshawa. Street Health 2014;1-24.

26. Macintyre AKJ, Montero VAR, Sagbakken M. From disease to desire, pleasure to the pill: a qualitative study of adolescent learning about sexual health and sexuality in Chile. BMC Public Health 2015;15:945. doi: 10.1186/s12889-015-22539.

27. Do LAT, Boonmongkon P, Paek SC. Hu Hong' (bad thing): parental perceptions of teenagers' sexuality in urban Vietnam. BMC Public Health 2017;17:226. doi: 10.1186/s12889-017-4133-y. 